\title{
The Inhibition Effect of 1-hydroxy-7-azabenzotriazole on X60 Pipeline Steel Corrosion in 1 M HCl Solution
}

\author{
Zhili Gong ${ }^{1,2}$, Shini Peng ${ }^{1, *}$, Jie Chen ${ }^{1}$, Lanzhou Gao ${ }^{1}$ \\ ${ }^{1}$ School of Urban Construction and Environmental Engineering, Chongqing University, Chongqing \\ 400044, China. \\ ${ }^{2}$ School of Chemistry and Chemical Engineering, Yulin University, Yulin 719000, China. \\ *E-mail: psn2008@126.com; 2170200265@qq.com
}

doi: $10.20964 / 2018.08 .23$

Received: 13 April 2018 / Accepted: 17 May 2018 / Published: 5 July 2018

\begin{abstract}
In this study, the effect of a benzotriazole derivative namely 1-hydroxy-7-azabenzotriazole (HOAT) on the inhibition of X60 pipeline steel corrosion in $1 \mathrm{M} \mathrm{HCl}$ solution was studied through complementary experimental approaches. Weight loss and electrochemical techniques including potentiodynamic polarization and electrochemical impedance spectroscopy (EIS), were employed to investigate the inhibition behavior of HOAT for steel corrosion. Weight loss analysis showed that inhibition efficiency of HOAT increases with its concentration and decreases with temperature. Electrochemical data provide good support to the weight loss study, and showed that HOAT behaves as a mixed-type corrosion inhibitor. Additionally, Langmuir adsorption model evidenced the adsorption of HOAT on the X60 steel surface via chemisorption mechanism.
\end{abstract}

Keywords: Corrosion Inhibition; X60 steel; EIS; AFM; Weight Loss.

\section{FULL TEXT}

(C) 2018 The Authors. Published by ESG (www.electrochemsci.org). This article is an open access article distributed under the terms and conditions of the Creative Commons Attribution license (http://creativecommons.org/licenses/by/4.0/). 